\title{
Corpo lésbico, história e formação docente: agenciando existência e visibilidade para criação de possíveis no/com o currículo
}

\section{Lesbian body, history and teacher education: managing existence and visibility for creating possible on/with the curriculum}

\author{
Danilo Araujo de Oliveira* \\ Marlucy Alves Paraíso* \\ Anderson Ferrari**
}

\begin{abstract}
RESUMO
Neste texto, a partir do relato de si de uma aluna que se identifica como branca, lésbica, jovem e de classe média, problematizamos a relação entre corpo lésbico, história e formação docente no/com o currículo. Trata-se de relato construído na disciplina de estágio do curso de Licenciatura em História de uma Universidade Pública Federal em Minas Gerais. Utilizando referenciais pós-críticos, argumentamos que a formação docente dessa aluna ocorre no corpo e com o corpo, constituindo-se como um processo histórico, composto por descontinuidades e rupturas, que permite o agenciamento de existências e visibilidades para a criação de possíveis no currículo. $\mathrm{O}$ artigo mostra, então, que a experiência da estudante lésbica produz uma pedagogia que faz questionar os padrões heteronormativos e leva à produção de conhecimentos sobre si, sobre seu corpo e sobre possibilidades outras que a fazem reinventar sua subjetividade e sua relação com a docência.
\end{abstract}

Palavras-chave: Corpo. História. Formação docente. Currículo.

${ }^{*}$ Universidade Federal de Minas Gerais. Faculdade de Educação. Belo Horizonte, Minas Gerais, Brasil. E-mail: danilodinamarques@hotmail.com - http://orcid.org/0000-0003-3222-3172 E-mail: marlucyparaiso@gmail.com - http://orcid.org/0000-0002-3542-4650

*** Universidade Federal de Juiz de Fora. Faculdade de Educação. Juiz de Fora, Minas Gerais, Brasil. E-mail: aferrari13@globo.com - http://orcid.org/0000-0002-5681-0753 


\begin{abstract}
In this text, from the self-report of a student who identifies herself as white, lesbian, young, and middle class, we problematize the relationship between the lesbian body, history, and teacher education in/with the curriculum. A report built on the internship discipline of the History Degree course at a Federal Public University in Minas Gerais. Using post-critical references, we argue that the teacher education of this student occurs in the body and with the body, constituting itself as a historical process composed of discontinuities and ruptures that allows the agency of existences and visibilities for the creation of possible ones in the curriculum. The article shows, then, that the lesbian student's experience produces a pedagogy that makes questioning heteronormative patterns and leads to the production of knowledge about herself, her body, and about other possibilities that make her reinvent her subjectivity and her relationship with teaching.
\end{abstract}

Keywords: Body. History. Teacher education. Curriculum.

\title{
Introdução
}

Quais as relações possíveis entre corpo, história ${ }^{1}$ e formação docente? Como os corpos interferem na constituição de professoras e professores? O que podem os corpos nas escolas? Quais os desafios e potencialidades dos corpos, quando são tomados como lugares em que se ensinam sobre os gêneros e as sexualidades? Temos aqui um conjunto de questões que são acionadas em função da transformação do corpo em campo de investigação, que provocam teorias, promovem deslocamentos, incitam políticas, escolas e sujeitos. Mais do que isso, questões que demonstram que não existem certezas sobre o corpo ou quando o tomamos como investimento em outras formas de saber, de ser e de estar nas escolas.

O corpo aparece como problemática importante de investigação nas obras de Michel Foucault (1988, 2004, 2013), devido ao seu interesse pelas relações de poder e pelos modos de subjetivação. Tanto o corpo como os sujeitos estão

1 Ao longo do artigo, vamos utilizar a palavra "história" com letra minúscula para nos referirmos à história vivida, ligada aos acontecimentos, ao passado que nos constitui e do qual fazemos parte. De forma diferente, vamos utilizar a mesma palavra com letra maiúscula para nos referir à disciplina acadêmica/escolar, que diz da produção e reprodução de um saber ligado à historiografia, à pesquisa e ao conhecimento. 
diretamente ligados aos processos históricos de suas constituições, aos discursos e às relações de poder-saber que nos constituem como detentores/as de nossos corpos, desejos e experiências.

O poder não é entendido aqui como aquele que emana de um centro, ou algo unilateral, mas como algo que se manifesta através das relações, sendo uma correlação de forças. Muito mais que uma instância negativa, o poder é uma rede produtiva que "produz coisas, induz ao prazer, forma saber, produz discurso" (FOUCAULT, 1998, p. 8). Por não ter apenas caráter repressivo, é possível àquele/a sobre o qual o poder se exerce ter capacidade de ação e de reação. Ainda para Foucault $(1998,2004)$, a compreensão das relações de poder não pode ser dissociada das relações de saber. $\mathrm{O}$ autor recusa a ideia de que, para constituir um saber, seria necessário suspender relações de poder. Segundo o autor, saber e poder estão mutuamente implicados, de modo que “(...) não há relações de poder sem constituição correlata de um campo de saber, nem saber que não suponha e não constitua ao mesmo tempo relações de poder" (FOUCAULT, 2004, p. 27).

Dessa forma, não há um sujeito externo a essas relações, e são essas relações que constituem os possíveis campos de conhecimento. Nesse entrelaçamento entre saber e poder, o poder não é algo apenas que reprime, impede, mas faz falar: "se ele é forte, é porque produz efeitos positivos no nível do desejo-como se começa a conhecer - e também no nível do saber. O poder longe de impedir o saber, o produz" (FOUCAULT, 1998, p. 148).

Nossos pertencimentos e significados que atribuímos aos corpos são resultados dessa relação de saber-poder. Muitas vezes, essa materialidade do corpo conduz à compreensão de que somos o que somos por nossa livre escolha ou, simplesmente, porque nascemos assim. Trata-se de uma forma de pensar que constrói pertencimentos aos nossos corpos e às nossas subjetividades. É esse entendimento que problematizamos neste artigo para incitar uma recusa de si em prol de outras estéticas de existência.

A estética da existência pode ser compreendida como "uma maneira de viver cujo valor moral não está em sua conformidade a um código de comportamento nem em um trabalho de purificação". No entanto, "depende de certas formas, ou melhor, certos princípios formais gerais no uso dos prazeres, na distribuição que deles se faz, nos limites que se observa, na hierarquia que se respeita" (FOUCAULT, 1984, p. 82). A estética da existência é, assim, um modo de sujeição, sendo, pois, uma das maneiras pelas quais o indivíduo se vincula a determinados valores e regras. Esse modo de sujeição tem características específicas, visto que o indivíduo "aceita certas maneiras de comportar-se e determinados valores porque decide e quer realizar sua vida e beleza que eles propõem" (CASTRO, 2009, p. 150). 
Para esse empreendimento de problematização, vamos tomar como provocador da escrita o relatório final de uma disciplina de um curso de formação docente. É o corpo lésbico que é eleito por uma estudante do curso de Licenciatura em História de uma Universidade Pública Federal em Minas Gerais para construir uma narrativa de si e de sua formação. Trata-se de uma mulher que se identifica como branca, lésbica, jovem, de classe média e estudante de História: Samara ${ }^{2}$. Acionando a estética da existência, Samara parece mobilizar "uma docência baseada na invenção de si mesmo e não na autodescoberta; alimentada pela relação com os outros e vivida como prática de liberdade" (LAPONTE, 2003, p. 79). Ela toma seu encontro com a sala de aula como o acontecimento em que o corpo e sua "verdade" tomam a centralidade.

Talvez a primeira coisa pra dizer sobre a minha entrada na Universidade e como isso reverberou na minha sexualidade e na maneira como eu aceitei a minha sexualidade - uma vez tendo eu mesmo aceitado, como eu passei a viver essa sexualidade -, é dizer [...] que a Universidade, em grande medida, foi o lugar físico, mas também do mundo das ideias, em que eu entendi que era possível ser um corpo lésbico no mundo, no espaço, no universo acadêmico, na minha vida e pra mim mesma. A minha trajetória foi muito marcada, até chegar na Universidade, pela heterossexualidade compulsória $^{3}$ (Relato de Samara registrado no Caderno de Notas do Estágio, 2020, p. 1).

Há um investimento, por parte da estudante, num "corpo lésbico" e no seu pertencimento a uma subjetividade lésbica. Também interessadas em discutir como os "discursos de gênero interpelam as professoras que agem segundo uma política de gênero marginal no território do natural e do real”, Patrícia Maciel e Maria Manuela Garcia (2018,p. 4) convidam a pensar em narrativas de professoras lésbicas como possibilidades de "desconstrução dos princípios que regem a normalização do gênero” (MACIEL; GARCIA, 2018, p. 4). A lesbianidade é assumida como um discurso que desestabiliza o binarismo de gênero, as identidades e a política sexual (MACIEL; GARCIA, 2018). Samara aprende e investe na potência do seu pertencimento a esse discurso de

2 As falas da estudante aparecerão ao longo do texto em itálico, para diferenciar das citações. Além disso, mantivemos o nome da estudante por uma reivindicação dela como parte do seu processo de visibilidade.

3 Os relatos são usados com a autorização prévia da estudante. 
lesbianidade, para assumir o protagonismo de experiências pessoais e docentes próprias de uma professora que leva o corpo em seus atravessamentos de gênero e sexualidade para a escola. Ao "relatar-se a si mesma" - prática entendida com base em Judith Butler (2015a) como uma ação ética e política que torna visíveis os enquadramentos das normas, que pautam as nossas condutas -, a estudante em formação faz uma exposição de um "quadro" ou "moldura" (BUTLER, 2015b) que evidencia um entrelaçamento do processo de formação docente com a constituição de sujeito. Afinal, no próprio relatar-se, como explicita Butler (2015a), há "descobertas" sobre si, sobre os "enquadramentos" e sobre as possibilidades de alianças para as resistências. Há, também, no relatar-se a si mesma, uma corresponsabilização pelas condições sociais que proporcionam determinados entendimentos sobre si. Por isso, os espaços de formação docente nas Universidades podem, com uma "aula que seja instigante e interessante", "que dê oportunidades ao improvável" (CORAZZA, 2012, p. 281), fazer rejeitar as normas impostas e traçar outros caminhos de escape ao aprisionamento da vida.

Ciente das dificuldades e das possibilidades de "uma aula" que seja "interessante" e "singular" (CORAZZA, 2012), o professor da disciplina de estágio na qual Samara estava matriculada provocou os alunos e as alunas a pensarem o estágio como momento na formação em que há a possibilidade de colocar tudo sob suspeita: as seleções de temas que compõem o currículo oficial $^{4}$, os modos de trabalhar esses temas, as relações estabelecidas, as visibilidades e invisibilidades dos corpos etc. Fez-se, então, na aula, um convite para que fossem pensadas outras temáticas que, comumente, não fazem parte do currículo, mas que estão presentes na vida, que interessam aos alunos e às alunas por sua atualidade, que se relacionam com processos históricos de constituição do pensamento e de formas de agir, ser e estar no mundo.

O convite não se limitava ao trabalho com o Ensino de História e com as escolhas curriculares, mas se prolongava para o trabalho com suas histórias de formação que antecederam a entrada na Universidade. Buscava-se estabelecer um entendimento de formação docente conectada com a produção de sujeitos. A partir das experiências, memórias e discursos, os/as alunos/as foram convocados/ as a pensar sobre que professores e professoras querem ser, assim como que alunos e alunas querem formar. Foi nesse "contexto de formação" que a estudante construiu seu relato de constituição como professora, como mulher lésbica e a sua intervenção na produção de um corpo lésbico. 
Provocada a pensar sobre esses momentos formativos, a aluna traz a materialidade do corpo: “(...) eu entendi que era possível ser um corpo lésbico no mundo, no espaço, no universo acadêmico, na minha vida e pra mim mesma". Trata-se de um relato de si mesma por meio do pertencimento a um corpo que fala de uma sexualidade, algo que nos remete a dois tempos ou momentos ligados ao corpo e ao sujeito e, portanto, que explicita uma ruptura, uma descontinuidade. $\mathrm{O}$ entendimento de que "era possivel", conforme relata a estudante, refere-se a uma descoberta, a uma passagem entre um tempo em que não era possível e um outro, em que um outro modo de vida se desenhava como possibilidade. Não se trata de qualquer possibilidade, mas daquela ligada à relação entre corpo, gênero, sexualidade, verdade e subjetividade. São essas vinculações que podem ser tomadas como condição de emergência dessa expressão e que nos vinculam à perspectiva foucaultiana de história, de corpo e de sujeito. Afinal, o corpo é "superfície de inscrição dos acontecimentos (enquanto a linguagem os marca e as ideias os dissolvem), lugar de dissociação do Eu (ao qual ele tenta atribuir a ilusão de uma unidade substancial), volume em perpétua pulverização" (FOUCAULT, 2013, p. 280).

É o próprio Foucault (2013) que fala da importância de se investigar a relação do corpo com a história. Ele diz: "a genealogia, como análise da proveniência, está, portanto, na articulação do corpo com a história. Ela deve mostrar o corpo inteiramente marcado pela história, e a história arruinando o corpo (FOUCAULT, 2013, p. 280). É a manutenção dessa articulação entre corpo e história que parece construir o corpo lésbico. E, para o que nos interessa, constitui também a professora lésbica implicada no seu processo de formação docente, assumindo esse corpo como lugar de informação.

A narrativa da estudante demonstra que é pelo corpo que a subjetividade é marcada e afrontada. É pelo corpo que a subjetividade procede como discurso e emerge como lugar de luta, de combate. É pelo corpo que a subjetividade emerge como saberes que mostram sua procedência estratégica de poderes (RIBEIRO, 2018). Interessado nos efeitos dessa história sobre os corpos, Foucault (2013), por meio da genealogia, questiona as linearidades e aposta nas disputas e nas relações de poder que atuam para produzir corpos e subjetividades de certos tipos. Ao olhar a história desse modo, a preocupação do genealogista é com o presente, ou seja, um trabalho que se constitui como uma necessidade de abrir possibilidades de vida no presente.

Esse modo de entender a história, que tem implicações não apenas teóricas, mas metodológicas, diz da forma como buscamos construir nossas problematizações neste artigo. Nesse sentido, nosso interesse neste estudo é, a partir de um modo de trabalhar história, inscrito na genealogia, discutir como ocorre a formação docente - entendida como um processo de subjetivação 
específico - em sua vinculação com o corpo. Assim, o argumento aqui desenvolvido é o de que a formação docente de uma aluna lésbica ocorre no corpo e com o corpo, constituindo-se como um processo histórico composto por descontinuidades e rupturas que permite o agenciamento de existências e visibilidades para a criação de possíveis. O artigo mostra, então, que a experiência da estudante lésbica no curso de formação na Universidade produz uma pedagogia que faz questionar os padrões heteronormativos e leva à produção de conhecimentos sobre si, sobre seu corpo e sobre possibilidades outras que a fazem reinventar sua subjetividade e sua relação com a docência.

\section{O corpo marcado pela história}

A narrativa de si mesma de Samara mostra um corpo marcado pela história e que fornece sentidos a ele. É com esse corpo entendido, por ela mesma, como local de saberes e de informações, que ela conduz a si mesma nas aulas de estágio. É um corpo que não performa as normas de gênero que estão na ordem do verdadeiro, do unívoco, do universal, construídas como naturais e legitimadas por uma série de discursos. "A minha trajetória foi muito marcada, até chegar na Universidade, pela heterossexualidade compulsória". É a partir de um "enquadramento" ou uma "moldura" da sexualidade, conforme caracteriza Judith Butler (2015b), que a aluna fala de si e de uma mudança na aceitação do seu desejo. É no "quadro" das experiências vividas na instituição que a aluna em formação tece narrativas sobre os escapes aos modos de vida antes capturados e que a faziam ter uma relação de aprisionamento com seu corpo, pertencente a um gênero e, portanto, a uma forma de sexualidade. É com a entrada na Universidade que ela passa a entender que corpo, gênero e orientação sexual não são naturais, e tampouco essências, mas algo instável, em transformação e, assim, revogável.

Desse modo, seu corpo incide numa ruptura com a linearidade sexo-gênero-sexualidade; uma transformação marcada por "até chegar na Universidade". A entrada na Universidade trouxe outra forma de saber, de entender seu corpo e a si mesma. A instituição oportunizou um outro "quadro", que permitiu à aluna falar de si mesma de um outro modo, conduzindo a expectativas em torno da escola e do que sabe sobre ser uma professora lésbica. Talvez, por isso, ela perceba uma tensão. Afinal, há uma "verdade" que diz quais corpos são possíveis na escola e como se devem narrar esses corpos. Conquanto se trate de um discurso que produz e que marca seu corpo como dissidente, exótico, estranho, ao mesmo tempo, a aluna negocia sua visibilidade, negociação esta que se dá com os saberes. 
[...] é o desafio de saber que as pessoas vão saber. Parece que não, mas isso é um grande desafio. E é com esse corpo que sabe que as pessoas sabem que eu chego até o João XXIII para o meu estágio com a turma do $6 C$ no ano de 2019. Foi um grande desafio, sobretudo porque, naquele momento... eu tinha acabado de me assumir em casa e de assumir o meu namoro. Eu namoro há dois anos com uma mulher que já convivia aqui em casa, e eu estava passando por uma série de dificuldades. Aquele era talvez o momento que era mais importante eu ter dentro de mim que estava tudo bem ser lésbica (Relato de Samara registrado no Caderno de Notas do Estágio, 2020, p. 3).

Dizer que se trata de um desafio é demonstrar que o saber que a constitui não é consenso, não é compartilhado por todos e todas. Mais do que isso, a narrativa de Samara mostra a descontinuidade da história. O desafio diz dos saberes que as pessoas vão acionar a partir do seu corpo definido como um corpo lésbico, que traz uma história que ela pretende desconstruir. Ao falar do corpo sendo marcado na história, Michel Foucault (2000) não está falando da história como linear, unívoca, evolutiva, progressiva e contada de um único ponto de vista, mas demarcando um trabalho do genealogista. O filósofo entende a história como descontínua, fragmentada, buscando, com isso, desestabilizar os essencialismos, as ideias de origem e os lugares de verdade de determinados saberes. Desse modo, "a genealogia é uma crítica da própria ideia de história" (RIBEIRO, 2018, p. 128). Uma crítica importante para a constituição de professores/as de História que leva a questionar a constituição dos saberes em História, nossas escolhas didáticas, nossos currículos, nossas aulas, o que é definido como a História oficial, os silenciamentos, enfim, um conjunto de problematizações que devem incidir sobre os sujeitos, tanto professores e professoras, como alunos e alunas.

O desdobramento dessa concepção de história para o Ensino de História pode ser traduzido numa questão: o que significa ensinar para a compreensão da História? Uma questão que significa um investimento nos alunos e nas alunas como capazes de colocar sob suspeita o que conhecem, entendendo que as formas de pensar e agir que nos constituem têm uma história. A formação nesse campo de conhecimento e nesse entendimento de história e do Ensino de História marcaram Samara no seu posicionamento e na produção política de si como professora de História que constrói suspeitas sobre as formas de conhecer, de ensinar determinados conteúdos, dos silenciamentos que a marcaram. O investimento em si mesma como professora lésbica de História é a aposta em outras histórias, outros currículos e outros sujeitos. Nessa mesma 
linha de condução, o interesse de Foucault (1988), tanto pelo corpo como pela história, se justifica em função do seu eixo central de investigação, que foi a relação entre sujeito e história. Nesse sentido, o autor constrói uma analítica do sujeito a partir de alguns modos de entendimento da história que são diferentes daqueles então instituídos.

Por um lado, há um modo de entender a história como objeto de descrição para pensar e colocar sob suspeita as bases do sistema dominante. Neste, a ordem do mesmo, do humano enquanto ser universal, da história como linha evolutiva se constitui como episteme, buscando reiterar a noção de que o presente é a evolução de uma sociedade. Outras histórias não têm lugar, ou são invisibilizadas, como critica Foucault (2000). Busca-se normalizar toda manifestação da diferença, que, ao recusar essa normalização, pode ser silenciada ou mesmo aniquilada. A busca pela origem, nesse modo de entender a história, acontece para revelar o lugar primeiro de tudo e, portanto, onde a verdade estaria ancorada. Por outro lado, há um outro modo de trabalhar com a história que, ao contrário, joga luz sobre o que é esquecido, apagado, silenciado na história dominante, demorando nas meticulosidades e nos acasos dos começos, nas lacunas. É associado a esse modo de entender a história que Foucault se volta para o sujeito, pois ele entende que "(...) era necessário que a história fosse contínua para que a soberania do sujeito fosse salvaguardada", assim como "era preciso reciprocamente que uma subjetividade constituinte e uma teleologia transcendental atravessassem a história para que ela pudesse ser pensada em sua unidade" (FOUCAULT, 2000, p. 118).

Assim, na genealogia, o sujeito não é protagonista da história, mas um efeito dos discursos históricos que o produzem de uma maneira específica. Não por acaso, Samara reconhece que estava vivendo um momento importante na sua vida pessoal - "Aquele era talvez o momento que era mais importante eu ter dentro de mim que estava tudo bem ser lésbica" -, fruto de uma mudança de entendimento sobre o que significa ser lésbica. "Eu ter dentro de mim que estava tudo bem ser lésbica" é uma frase que traz um outro momento em que ser lésbica não era considerado como algo positivo. Samara vai sendo constituída como efeito desses discursos, os quais, em determinado momento, atribuem à lesbianidade uma orientação negativa e, em outro, uma positiva. Existe uma história como ruptura dessa forma de entendimento. No Brasil, desde a década de 1990, vem-se ampliando a visibilidade das lesbianidades, assim com as demais "minorias sexuais", que se tornaram muito mais visíveis do que antes (LOURO, 2000).

Segundo Guacira Louro (2000), esse movimento foi responsável por mudanças nos sujeitos e em suas formas de assumir e compreender os gêneros e as práticas sexuais inscritas nos seus corpos, mas, sobretudo, foi 
capaz de gerar efeitos nas maneiras de os sujeitos se relacionarem com os saberes e com os prazeres. Samara é tributária desse movimento sexual, de maneira que sua lesbianidade não é apenas entendida "como um referente da verdade do eu, mas é um movimento sexual radical", quando as lésbicas são chamadas a falarem de si "e sobre o que pensam do mundo no processo de ensino e aprendizagem" (MACIEL; GARCIA, 2018, p. 9). A narrativa de Samara adquire força a partir da perspectiva foucaultiana, já que havia, para Foucault (1984), um exercício específico ao pensar a história. Trata-se de um exercício filosófico em que o sujeito, ao pensar sua própria história, pode pensar diferentemente do que pensava.

Dessa forma, o autor chama atenção para a necessidade de uma atitude "crítica permanente de nosso ser histórico" (FOUCAULT, 2000, p. 345), ou dito de outro modo, "é preciso tentar fazer a análise de nós mesmos como seres historicamente determinados" (FOUCAULT, 2000 345). Essa atitude nega a existência dualista entre racionalidade e irracionalidade, como também uma suposta essência universal do ser humano. Nesse sentido, a pesquisa genealógica se constitui considerando a "contingência que nos fez ser o que somos a possibilidade de não mais ser, fazer ou pensar o que somos, fazemos ou pensamos" (FOUCAULT, 2000, p. 348).

Na relação com essa perspectiva de história, Foucault (1998) confere ao corpo certa importância, entendido como "uma marca ou estigma dos acontecimentos; o corpo é interstício, espaço que emerge aquilo pelo que se luta, isto é, lutar vazio que dará chance a Foucault fazer sua genealogia da subjetividade" (RIBEIRO, 2018, p. 147). De acordo com o filósofo, "sobre os corpos se encontra o estigma dos acontecimentos passados, do mesmo modo que dele nascem os desejos, os desfalecimentos e os erros (FOUCAULT, 2000, p. 267).

Foucault (1998) entende o corpo como resultado e como o efeito de um discurso, portanto, por ele produzido. As investigações sobre o corpo, nos termos delineados da genealogia, inscrevem-se no estudo do problema, e não da totalidade. Isso significa que há uma indiferença para com a obrigação de tudo dizer. Assim, não se pretende reconstituir exatamente tudo que aconteceu em relação a um objeto de pesquisa, mas descrever "o regime de práticas" (FOUCAULT, 2006, p. 338) que constituiu, historicamente, um determinado objeto ou fenômeno. Ao focar nossas análises na formação docente, no corpo e com o corpo, inspiramo-nos nesse modo de investigação, priorizando, pois, as condições de emergência, as relações de poder que produzem essa experiência histórica. A aposta, portanto, tanto em Foucault quanto nas inquietações de Samara, é na crítica como pesquisa histórica nos termos da genealogia. 
Nesse sentido, procuramos tratar simultaneamente os discursos que articulam o que pensamos, dizemos e fazemos e os acontecimentos históricos, voltando-nos, dessa forma, para a "contingência que nos fez ser o que somos a possibilidade de não mais ser, fazer ou pensar o que somos, fazemos ou pensamos" (FOUCAULT, 2000, p. 348). Samara, ao pensar seu corpo, parece "colocar-se à prova da realidade e da atualidade, para simultaneamente apreender os pontos em que a mudança é possível e desejável e para determinar a forma precisa a dar a essa mudança" (FOUCAULT, 2000, p. 348).

Assumir que o corpo é história significa afirmar que ele é resultado de construção e de modificações ao longo do tempo. Assim como Foucault, Denise Sant'Ana (2000), Carmen Lúcia Soares (2011), George Vigarello (2003), dentre outros autores e autoras, vêm discutindo a centralidade do corpo na atualidade. Isso é feito sem esquecer seu atravessamento na história, chamando atenção para o fato de que o corpo sempre foi entendido e, portanto, vivido, de diferentes maneiras ao longo do tempo e por distintas culturas, colocando sob suspeita o que chamamos de anormal, exótico, excêntrico. Como o entendimento do corpo como construção não se limita aos seus aspectos social e cultural, mas também ao biológico, o corpo biológico é visto como resultado dos discursos e relações de saber-poder que vão variando em suas temporalidades.

Dizendo dessa temporalidade dos discursos em torno do corpo, não podemos deixar de ressaltar a importância dos discursos feministas no que diz respeito à relação entre corpo, gênero, sexualidade, visto que os feminismos marcam uma ruptura do entendimento do corpo como local de investimento dos discursos na construção das desigualdades entre homens e mulheres. Os feminismos submeteram a uma análise crítica qualquer percepção moral ou divisão social que se fundamentava na diferença fisiológica dos corpos masculinos e femininos, colocando sob escrutínio a noção de que o corpo biológico é um destino natural. Nesse sentido, Butler (2003, p. 27) argumenta que "[...] não há como recorrer a um corpo que já não tenha sido sempre interpretado por meio de significados culturais". Inscrito nessa compreensão, o conceito de gênero da autora está diretamente relacionado ao corpo. Gênero é a "estilização repetida do corpo, um conjunto de atos repetidos no interior de uma estrutura reguladora altamente rígida, a qual se cristaliza no tempo para produzir a aparência de uma substância, de uma classe natural de ser" (BUTLER, 2003, p. 59).

Essas disputas em torno do corpo também influenciaram o debate no campo da Educação, principalmente no currículo e na formação docente. Assim, a afirmação feita há quase duas décadas por Guacira Lopes Louro (2000, p. 60) de que o "corpo parece ter ficado fora da escola. Essa é, usualmente, a primeira impressão quando observamos as mais consagradas teorias educacionais ou os 
cursos de preparação docente", os quais vêm se modificando com a influência de diferentes teorizações que vêm mostrando a primazia do corpo nas lutas políticas e culturais, na pedagogia e na produção de sujeitos. Assim, o surgimento do campo das Relações de Gênero, Sexualidade e Educação, com as pautas e reivindicações dos Movimentos Sociais, como o Negro e o $\mathrm{LGBT}^{5}$ e a entrada de pessoas LGBT nos programas de pós-graduação com novas temáticas e perspectivas teóricas que incorporam o corpo e suas histórias nos movimentos de pesquisa, demonstraram que o corpo nunca esteve fora da escola, dos cursos de formação e dos currículos. Ele tem confirmado sua centralidade não para manutenção do seu entendimento e de seu lugar como natural e dado, mas para colocar sob debate nossas formas de saber, questionar os discursos que nos constituem e como possibilidade de outras subjetividades. Foi nesse contexto de transformação do corpo nos processos de formação e nas escolas que a estudante lésbica relata a si mesma como professora de História que modifica sua relação consigo mesma, com seu corpo, com a docência e com o currículo.

Quando eu chego na frente daquela turma toda eu sou um corpo... eu sou um corpo que eu sei que as pessoas sabem... [...] qual era o meu tema? [...] Eu fiz um link histórico trabalhando similaridades e diferenças entre as relações homoeróticas da Antiguidade e as relações homoafetivas da contemporaneidade. Mas eu construi uma linha do tempo entre esses dois intervalos, e fui colocando marcos históricos de conquista da comunidade $L G B T$ e marcos históricos de retrocessos, como por exemplo, países que ainda punem relações homoafetivas com pena de morte; Liberação do casamento civil; quando a OMS tira a homossexualidade da lista de doenças mentais. Construi uma linha do tempo gigantesca e colei no quadro, super colorida, com as cores da bandeira LGBT. Quando os alunos entraram em sala, eu estava com a minha roupa mais sapatonesca (risos) [...] era uma roupa que eu gosto, que eu me sinto muito bem com ela. Não é uma roupa que performa muito a feminilidade. Não quer dizer que eu não goste de roupa que performa feminilidade, pois já fui para o estágio de vestido. Mas naquele dia eu queria muito, de alguma forma,

5 Não há um consenso do uso dessa sigla que se encontra em constante tensionamento e disputa. "Essas tensões evidenciam que efetivamente somos muito diferentes dentro e fora da própria sigla" (COLLING, 2018, p. 418). No entanto, aqui, adotamos a sigla utilizada pela Associação Brasileira de Lésbicas, Gays, Bissexuais, Travestis, Transexuais e Intersexos (ABGLT), organização que tem como objetivo e a missão, desde 1995, de promover ações que garantam a cidadania e os direitos humanos de LGBTs. Para mais detalhes sobre os tensionamentos de construção da sigla, ver o livro “Sopa de Letrinhas?”, da autora Regina Facchini (2005). 
afirmar a minha sexualidade visualmente num primeiro olhar e eu sabia que a melhor forma de fazer isso era usando roupas que eu gosto muito e que não performam feminilidade. Então eu fui com uma roupa que se eles olhassem [...] mais analiticamente eles saberiam que eu era lésbica... que eu sou lésbica. Eu estava com uma calça vermelha e uma blusa masculina, uma camiseta masculina superestilosa, cabelo curtinho, de alargador, assim... uma série de códigos que indicavam para eles, visualmente, que eu sou uma mulher lésbica (Relato de Samara registrado no Caderno de Notas do Estágio, 2020, p. 4).

O investimento da Samara na experiência de estágio é, com o seu corpo, transformar a si mesma e suas ações como professora. Ela entende primeiramente que, ao chegar na frente da turma, é um corpo que chega e aciona uma política das identidades em que os alunos e as alunas são convocados/as a dar significados de gênero e sexualidade àquele corpo. Um corpo produzido para tensionar os regimes de visibilidade estabelecidos como normais e corretos. Assim, ela recorre àquilo que pode ser o mais transgressor naquela experiência: mostrar um corpo que é expressivamente dissidente. Seu corpo se constituiu como a própria pedagogia corporificada. Sua intenção é a de, com o seu corpo, colocar no currículo ensinamentos que pareciam importantes, trazendo-o, assim, para o campo do visível e do inteligível. É com seu corpo que Samara pretende criar suspeitas e levantar curiosidades nos/nas alunos/as. A atuação da aluna por meio da disciplina de estágio vincula-se ao meio discursivo/cultural dos discursos da lesbianidade "nos quais a estabilidade da estrutura binária do sexo é subvertida, as categorias das identidades são abertas e a política da identidade sexual é compreendida como produção política e cultural" (MACIEL; GARCIA, 2018 , p. 4). Nesse sentido, em meio a uma cultura fortemente heteronormativa e disciplinar, que produz e governa os corpos lésbicos de professoras em seu exercício da docência, o que Samara pretende com seu corpo é, conforme ela fala no relato de si, afirmar sua sexualidade, tornar visivel que é uma mulher lésbica, fazer os/as alunos/as saberem que ela é uma lésbica.

A estudante/professora fala de uma transformação para mostrar um corpo do qual não se pode fugir, mas que é assumido como uma ligação para a atualidade e para pensar a História e o Ensino de História. Existe um saber que organiza todo seu entendimento a respeito do que ela é, do que ela espera dos outros e o que isso diz da relação necessária entre o que se espera de uma professora no exercício da sala de aula. Mas falar desse saber está atravessado, o tempo todo, pelas relações de poder, como afirma Foucault (1988), quando argumenta que falar da sexualidade é falar da história, como discurso atravessado pelas relações de poder. A história da sexualidade, para o 
autor, é a história dos discursos. Uma história à qual aprendemos a nos vincular, sobretudo na condução de nossos corpos, desejos e subjetividade; que nos faz confessar, pelo menos para nós mesmos/as, sobre o que desejamos para saber o que somos, como se nossas "verdades" estivessem em algo que precisa ser descoberto para que possamos saber quem somos. Esse jogo do saber faz a estudante classificar o seu momento de intervenção didática no estágio como "um grande desafio", por se tratar de um corpo lésbico na escola. Adjetivar sua presença dessa forma só parece possível porque tem um conhecimento sobre o que espera de um corpo lésbico no espaço escolar, algo que ela vai aprendendo e vai incorporando ou corporificando como preocupação adicional à formação docente. Isso faz a sua formação ser distinta da que ocorre com outras estudantes heterossexuais na mesma turma.

A formação docente não diz somente de uma preparação objetiva estabelecida com o programa das disciplinas, com o desenho curricular da formação, com as leituras recomendadas, com as práticas docentes. Ela também é resultado das relações subjetivas, daquilo que acontece fora da Universidade, que envolve outras experiências, emoções, conflitos, prazeres e que influenciam na formação. Afinal, ser e estar professor ou professora na escola não trata apenas de mente, mas também de um corpo que se apresenta e que traz, junto de si, sua história, do mesmo modo que um currículo também traz essa história e, juntos, podem movimentar "o presente que é nosso problema e limite" e o "futuro que queremos mudado" (CORAZZA, 2001, p. 14). Um corpo lésbico traz consigo a história da homossexualidade, uma história que é datada e que diz de um surgimento vinculado ao discurso médico como uma doença (FOUCAULT, 1988).

Não por acaso, a estudante relaciona a tensão que estava vivendo fora da formação com aquela que a esperava como estagiária na sala de aula, pela primeira vez. Diz ela: "Foi um grande desafio, sobretudo porque, naquele momento... eu tinha acabado de me assumir em casa e de assumir o meu namoro". Assumir-se em casa junto à família acabou por fortalecer suas escolhas didáticas como, por exemplo, a temática da aula, seu investimento no corpo com a escolha da sua "roupa mais sapatonesca" e seu posicionamento de se assumir lésbica para os alunos e as alunas. Como lembra Judith Butler (2019, p. 12), "pensar o corpo como construído demanda repensar o significado da construção de si". Além disso, diz a autora, "se certas construções parecem constitutivas, $[. .$.$] poderíamos sugerir que os corpos apenas surgem, apenas$ perduram e apenas vivem dentro das restrições produtivas de certos esquemas de gênero altamente regulatórios" (BUTLER, 2019, p. 12). O corpo lésbico é entendido, portanto, dentro desses "esquemas de gênero altamente regulatórios", como afirma Butler (2019, p. 12). 
Ao investigar as experiências de gênero de mulheres professoras no magistério, Maciel e Garcia (2018) mostraram como essas experiências se "constituíram um conhecimento próprio e uma mediação das situações vividas por elas como professoras nas escolas e como problematizaram a essencialização das identidades sexuais e a heterossexualização dos conteúdos e práticas escolares" (MACIEL; GARCIA, 2018, p. 4). Algo próximo pode ser percebido a partir do relato de si mesma de Samara. Além do corpo lésbico da estudante emergir no currículo escolar como uma pedagogia própria que instaura uma política de luta por visibilidade, a estagiária mobiliza saberes históricos que vão de encontro à heterossexualização dos conteúdos e práticas escolares. É desse modo que ela compõe, com o seu corpo, a criação de outros possíveis no currículo.

\section{Saberes históricos que produzem inteligibilidade para o corpo lésbico}

Compreendendo que o estágio seria um desafio, Samara agencia a existência e a visibilidade do seu corpo na escola em uma prática curricular. Para isso, ela recorre a saberes históricos que podem produzir inteligibilidade para o corpo lésbico e transforma o currículo. No seu plano de aula, a proposta era, primeiramente, trabalhar com as "similaridades e diferenças das relações homoeróticas da Antiguidade e as relações homoafetivas da contemporaneidade". Um recorte histórico grande, mas que só é possível porque as questões das homossexualidades passaram a ser entendidas em uma perspectiva histórica, um ganho advindo dos estudos gays e lésbicos a partir da redemocratização brasileira (MACRAE, 1990). Contudo, na sua preparação para a aula, Samara não diz somente de uma preocupação com o conteúdo, mas também com a apresentação do seu corpo, entendido como detentor de informação e, portanto, que dialoga com a temática. No desenvolvimento da aula, podemos localizar algumas estratégias: demarcação das conquistas e retrocessos; interferir na estética da sala, deixando-a com as cores da bandeira LGBT; uso de ornamentos que parecem vincular seu corpo lésbico a essa História que quer ensinar. A partir dessas estratégias, instaura-se um modo de viver e estar na formação docente, de maneira que podemos inferir que elas ensejam políticas de reconhecimento da tessitura de uma inteligibilidade lésbica. Nesse sentido, os saberes selecionados pela estudante "incorporam e produzem significados corporificados sobre gênero e sexualidade e, assim, concorrem tanto para processos de corporificação como para a distribuição de visibilidades; em suma, para agenciar políticas de reconhecimento" (RANNIERY, 2016, p. 54). 
Estar naquela aula de estágio, constituindo-se como docente lésbica, pode ser entendido como um processo imbricado com esses saberes selecionados. Esses saberes parecem ser um daqueles "recursos [que] devemos possuir para trazer para a comunidade humana aqueles humanos que não foram considerados parte do reconhecidamente humano" (BUTLER, 2004, p. 225). Assim, no relato de si mesma da estudante lésbica, é evidente que o corpo lésbico é alçado ao reconhecimento. Desse modo, parece que o tema preparado pela aluna não é apenas uma escolha aleatória, mas um investimento que se afirma como um importante campo de força que incide na produção do seu corpo e na sua visibilidade em sala de aula, disponibilizando, assim, esquemas de inteligibilidade a partir dos quais o corpo lésbico pode existir. É importante considerar essas temáticas da aula de História, quando entram na composição do corpo da estudante lésbica.

Há um histórico investimento da escola como um espaço de normalização, de forma que os saberes majoritariamente nela difundidos operam "apenas com um modo adequado, legítimo, normal de masculinidade e de feminilidade e uma única forma sadia e normal de sexualidade, a heterossexualidade" (LOURO, 2010, p. 43-44). As temáticas escolhidas podem evidenciar as disputas no que se refere à construção das homossexualidades e heterossexualidades, colocando, talvez, tensões nas normas que organizam a heterossexualidade como natural e dada. Trata-se de temáticas que buscam problematizar "as formas através das quais as diferenças são constituídas e nomeadas" (LOURO, 2010, p. 46), logo, como uma produção histórico-discursiva e investimento na constituição de alunos e alunas de um determinado tipo. Percebe-se como a presença do corpo lésbico e da subjetividade lésbica ameaçam o que já está instituído e cristalizado no currículo. Dito de outro modo, podem mostrar "como os sujeitos ditos marginais minam a estabilidade de uma pedagogia convencional" (MACIEL; GARCIA, 2018, p. 7). Mais especificamente, no que se refere às lésbicas, percebe-se como elas, "na ausência de um conhecimento sobre sua vida na educação, levantam questões sobre o saber/conhecer na sala de aula" (MACIEL; GARCIA, 2018, p. 7).

Nesse sentido, mais do que fazer emergir experiências silenciadas na escola, Samara fornece um outro sentido à História e à Educação, ao trazer essas temáticas novas no campo da História para dar lugar e visibilidade a si mesma a partir do seu corpo como um corpo lésbico que é construído, também, por meio dessas tensões entre saberes, poderes e sujeitos. Essa ação com os saberes junto aos alunos e às alunas também serve à Samara na sua experiência de se tornar professora lésbica. 
De modo parecido, a tentativa de fazer com que "gênero e sexualidade sejam considerados temas não escolares" (PARAÍSO, 2018) mostra quais modos de vida e corpos são autorizados e possíveis: os modos de vida que correspondem às normas de gênero e os corpos heterossexuais. Paraíso (2018) afirma que estratégias de poder que tentam "coibir e impedir qualquer trabalho na escola com os temas gênero e sexualidade estão contribuindo exatamente para aumentar o número de vidas não vivíveis; aumentar o número de mortes sociais" (PARAÍSO, 2018, p. 54). Nesse sentido, os temas escolhidos pela estudante na disciplina de Estágio em Ensino de História podem funcionar como uma estratégia na qual "a inteligibilidade se produz, contribuindo para que experiências que escapam à estreiteza da hegemonia heterossexual possam interagir com as condições históricas do tempo presente" (RANNIERY, 2016, p. 56). Desse modo, não somente os temas escolhidos se constituem como discurso, mas o próprio corpo da aluna está compondo esse discurso e se produzindo como tal para a produção de possíveis no currículo e na formação docente.

Consideramos que "o que está em jogo em um currículo é a constituição de modos de vida, a tal ponto que a vida de muitas pessoas depende do currículo" (PARAÍSO, 2010, p. 588). Samara parece ser atravessada de algum modo por essa compreensão, de maneira que é no currículo que ela quer intervir, seja acionando seu corpo como local de inscrição e produção de saberes outros ou inserindo no currículo temáticas que afirmem seu modo de vida, tornando-o vivível e visível. No processo de constituir a subjetividade de uma professora lésbica e a visibilidade de um corpo que performa essa subjetividade, a experiência de Samara vincula-se ao "enfrentamento das professoras lésbicas na crítica a uma perspectiva curricular que tem como base os ideais regulatórios da heterossexualidade, de uma pedagogia que delega os sujeitos homossexuais para o campo do abjeto e do estranho, e até mesmo o do patológico" (MACIEL; GARCIA, 2018, p. 6). Constituir-se como uma professora lésbica, com um corpo lésbico possível na escola, mostra-se como um investimento na trajetória docente, visto que a experiência no estágio era, para a professora, a primeira experiência como docente. Ela afirma sua intenção de se mostrar como lésbica, desde o primeiro momento em que estaria diante de uma turma, como um momento de passagem importante para sua constituição como professora e como lésbica. 


\section{Considerações finais}

O relato de si mesma na experiência de estágio sobre o processo de se constituir como professora lésbica acontece no/com o seu corpo lésbico, por meio do qual há "a criação de uma pedagogia que funciona mediante o questionamento da materialidade dos corpos e da sexualidade" (MACIEL; GARCIA, 2018, p. 6). A partir do modo de expressar sua sexualidade acionando seu corpo, mostrando-o dissidente, fora da norma, Samara, na experiência de estágio, transforma a si mesma e o currículo, constituindo um modo de ser docente. Estabelece, assim, uma relação consigo mesma, dentro dos códigos estabelecidos sobre o corpo lésbico na escola, ou seja, algumas maneiras próprias de produzir modos de ser docente.

Mostramos aqui que o investimento no corpo e em si mesma/o é um investimento em outra forma de pensar a Educação, a História, o Ensino de História, o currículo, as escolas e os sujeitos. Samara responde a duas perguntas importantes para o exercício da docência: quem eu penso que os meus alunos e alunas são? Quem eu quero que eles e elas sejam? Duas perguntas que, segundo Elizabeth Ellsworth (2001), são de importância crucial no currículo e nas práticas educacionais, para que sejam acertados os "modos de endereçamentos", isto é, para que possamos endereçar aos/as nossos/as estudantes discursos que os façam pensar, rir ou chorar, que sejam capazes de mudar modos de ser e viver e que, portanto, apostam na Educação como processo de mudança social (ELLSWORTH, 2001).

Ao fazer isso, Samara demonstra o seu entendimento de que a Educação é um processo de olhar para o mundo, significar as coisas e os sujeitos, acionar nossas formas de pensar, ser e agir. Samara reivindica e aposta numa ação de colocar sob suspeita nossas formas de ser e pensar a partir de si mesma, porque essa forma de agir parece provocar um des-reconhecimento do gênero como possibilidade de mudança do que conhecemos e como agimos. Um desaprender que também é importante para aprender outras coisas de outros modos.

O processo educativo que Samara faz circular está para além da transmissão de conteúdos. Ele se apresenta como implicado na afetação nos sujeitos convidando-os a pensar o corpo como estando em constante construção. Isso é da maior importância, já que os corpos daqueles que, antes eram considerados "anormais", estão longe de serem dóceis. Na atualidade, esses corpos, no campo da Educação, podem e devem ser entendidos como desafiantes e potentes nas suas possibilidades de construir outros modos de subjetivação, outros currículos e outras docências. 


\section{REFERÊNCIAS}

BUTLER, Judith. Problemas de gênero: feminismo e subversão da identidade. Tradução de Renato Aguiar. Rio de Janeiro: Civilização Brasileira, 2003.

BUTLER, Judith. Undoing gender. New York: Routledge, 2004.

BUTLER. Judith. Corpos que importam: Os limites discursivos do "sexo". São Paulo: n-1 edições, 2019.

BUTLER, Judith. Relatar a si mesmo: crítica da violência ética. Belo Horizonte: Autêntica, 2015a.

BUTLER, Judith. Quadros de Guerra: quando a vida é passível de luto? Rio de Janeiro: Civilização Brasileira, 2015b.

CASTRO, Edgardo. Vocabulário Foucault: um percurso pelos seus temas, conceitos e autores. Belo Horizonte: Autêntica, 2009.

COLLING, Leandro. A emergência dos artivismos das dissidências sexuais e de gêneros no Brasil da atualidade. Revista sala preta, São Paulo, v. 18, n. 1, 2018.

CORAZZA, Sandra Mara. O que quer um currículo?: pesquisas pós-críticas em educação. Rio de Janeiro: Vozes, 2001.

CORAZZA, Sandra Mara. Didaticário de Criação: aula cheia, antes da aula. In: ENCONTRO NACIONAL DE DIDÁTICA E PRÁTICAS DE ENSINO, 16., 2012, Campinas: FE/UNICAMP, 2012. p. 278-284. E-book. Disponível em: http://endipe.pro. br/ebooks-2012/0023s.pdf. Acesso em: 18 set. 2020.

ELLSWORTH, Elizabeth. Modos de endereçamento: uma coisa de cinema; uma coisa de educação também. In: SILVA, Thomaz Tadeu da. Nunca fomos humanos - nos rastros do sujeito. Belo Horizonte: Autêntica, 2001. p. 7-76.

FACCHINI, Regina. Sopa de letrinhas? Movimento homossexual e produção de identidades coletivas nos anos 90. Rio de Janeiro: Garamond, 2005.

FOUCAULT, Michel. História da sexualidade I: a vontade de saber. Rio de Janeiro: Graal, 1988.

FOUCAULT, Michel. História da sexualidade II: o uso dos prazeres. 3. ed. Rio de Janeiro: Edição Graal, 1984.

FOUCAULT, Michel. Microfísica do Poder. Rio de Janeiro: Graal, 1998

FOUCAULT, Michel. Ditos e escritos II: arqueologia das ciências e história dos sistemas de pensamento. Rio de Janeiro: Forense, 2000. 
FOUCAULT, Michel. Vigiar e Punir: nascimento da prisão. Petrópolis: Vozes, 2004.

FOUCAULT, Michel. Diálogo sobre o poder. In: Ditos e escritos IV: estratégia, podersaber. 2. ed. Rio de Janeiro: Forense Universitária, 2006. p. 335-351, v. 4.

FOUCAULT, Michel. Ditos e escritos II: Arqueologia das ciências e história dos sistemas de pensamento. Rio de Janeiro: Forense Universitária, 2013.

LAPONTE, Luciana Gruppelli. Do Nietzsche trágico ao Foucault ético: sobre estética da existência e uma ética para docência. Educação e Realidade, Porto Alegre, n. 2, v. 28, p. $69-82$, jul./dez. 2003.

LOURO, Guacira Lopes. Corpo, Escola e Identidade. Revista Educação \& Realidade, Porto Alegre, v. 25, n. 2, p. 59-76, jul/dez. 2000.

LOURO, Guacira Lopes. Currículo, gênero e sexualidade. O "normal", o "diferente” e o "excêntrico". In: LOURO, Guacira Lopes; FELIPE, Jane; GOELLNER, Silvana Vilodre (org.). Corpo, gênero e sexualidade: um debate contemporâneo na educação. Petrópolis, RJ: Vozes, 2010. p. 43-53.

MACIEL, Patrícia Daniela; GARCIA, Maria Manuela Alves. A lesbianidade como arte da produção de si e suas interfaces no currículo. Revista Brasileira de Educação, Rio de Janeiro, v. 23, p. 1-18, 2018.

MACRAE, Edward. A construção da igualdade: identidade sexual e política no Brasil da abertura. Campinas: Editora da Unicamp, 1990.

PARAÍSO, Marlucy Alves. Lutas entre culturas no currículo em ação na formação docente. Educação e Realidade, Porto Alegre, v. 21, n. 1, p. 137-157, 1996.

PARAÍSO, Marlucy Alves. Diferença no currículo. Cadernos de Pesquisa, São Paulo, v. 40, n. 140 , p. 587-604, maio/ago. 2010.

PARAÍSO, Marlucy Alves. Fazer do caos uma estrela dançarina no currículo: invenção política com gênero e sexualidade em tempos do slogan "ideologia de gênero". In: PARAÍSO, Marlucy Alves; CALDEIRA, Maria Carolina da Silva (org.). Pesquisas sobre currículos, gêneros e sexualidades. Belo Horizonte: Mazza, 2018. p. 23-55.

RANNIERY, Thiago. Corpos feitos de plástico, pó e glitter: currículos para dicções heterogêneas e visibilidades improváveis. 2016. Tese (Doutorado em Educação) Universidade do Estado do Rio de Janeiro, Rio de Janeiro, 2016.

RIBEIRO, Carlos Eduardo. Nietzsche, a genealogia, a história: Foucault, a genealogia, os corpos. Cad. Nietzsche, Guarulhos, v. 39, n. 2, p. 125-160, maio/ago. 2018.

SANT'ANA, Denise Bernuzzi de. Descobrir o corpo: uma história sem fim. Revista Educação \& Realidade. Porto Alegre, v. 25, n. 2, p. 49-58, jul./dez. 2000. 
OLIVEIRA, D. A.; PARAÍSO, M. A.; FERRARI, A. Corpo lésbico, história e formação docente...

SOARES, Carmen Lúcia. Corpo e História. São Paulo: Autores Associados, 2011.

VIGARELLO, Georges. A história e os modelos do corpo. Revista Pró-Posições, v. 14, n. 2 (41), p. 21-29, maio/ago. 2003.

Texto recebido em 30/09/2020.

Texto aprovado em 24/11/2020. 